\title{
UTROŠAK ARMATURE I BETONA KOD IZGRADNJE KONSTRUKTIVNOG DIJELA ARMIRANO-BETONSKE MONTAŽNE HALE U ZAVISNOSTI OD PODUŽNOG RAZMAKA STUBOVA I GLAVNIH NOSAČA
}

\author{
Ismet Gušić ${ }^{1}$ \\ Bilal Hodžić ${ }^{2}$ \\ Amela Šljivić 3
}

УДК: 691.328.1

DOI:10.14415/konferencijaGFS 2015.013

Rezime: $U$ ovom radu istraživan je utrošak armature i betona kod izgradnje armiranobetonskih montažnih hala u zavisnosti od podužnog razmaka stubova i glavnih nosača. Da bi se došlo do potrebnih podataka urađen je statički proračun, nacrti armature, specifikacije armature za izgradnju konstruktivnog dijela armirano-betonske montažne hale u četiti različita slučaja podužnog razmaka krovnih nosača tip „, $A$ “ istog raspona $l=18,0 \mathrm{~m}$. Predmetne hale su računate sa podužnim razmakom krovnih nosača $i$ stubova $(\lambda=6,0 \mathrm{~m}, 7,5 \mathrm{~m}, 10,0 \mathrm{~m} i \mathrm{12,0} \mathrm{m})$. Na osnovu nacrta objekta, nacrta armature $i$ specifikacije armature urađen je predmjer betona i armature za dispozociju hale sa podužnim razmakom stubova i krovnih nosača $(\lambda=6,0 \mathrm{~m}, 7,5 \mathrm{~m}, 10,0 \mathrm{~m}$ i $12,0 \mathrm{~m})$. Dobivene vrijednosti potrebne armature $i$ betona su prikazane tabelarno. Na osnovu tabela potrebne armature $i$ betona za izgradnju montažne armirano-betonske hale za pojedine podužne razmake stubova i glavnih nosača urađena je zbirna tabela. Analizom zbirne tabele došlo se do zaključka o najpovoljnijem rasteru u okviru ispitivanih, i dale se preporuke za buduće projektante.

Ključne riječi: montažne konstrukcije, armatura, beton, raster i najpovoljniji raster

\section{OPIS ISTRAŽIVANJA}

U ovom radu je izvršeno istraživanje utroška armature i betona u zavisnosti od podužnog razmaka stubova i glavnih nosača kod izgradnje konstruktivnog dijela armirano-betonske montažne hale. Uzeta je armirano-betonska montažna hala dimenzija $18,0 \times 60,0 m$.

Sekundarni nosači su „T“ grede preko kojih je pokriven sendvić lim. Glavni nosači su tip „A“ raspona 18,0 m podužnog razmaka stubova i krovnih nosača $(\lambda=6,0 \mathrm{~m}, 7,5 \mathrm{~m}$, $10,0 \mathrm{~m} \mathrm{i} 12,0 \mathrm{~m}$ ).

\footnotetext{
${ }^{1}$ Dr.sci Ismet Gušić, dipl.ing.građ., Rudarsko-geološko-građevinski fakultet Univerziteta u Tuzli

${ }^{2}$ Mr.sci Bilal Hodžić, dipl.ing.građ., Rudarski institut Tuzla

${ }^{3}$ Amela Šljivić, Ma dipl.ing.arh., Ahitektonski fakultet Univerziteta u Sarajevu
} 


\section{$41^{\text {th }}$}

International conference

Contemporary achievements in civil engineering 24. April 2015. Subotica, SERBIA

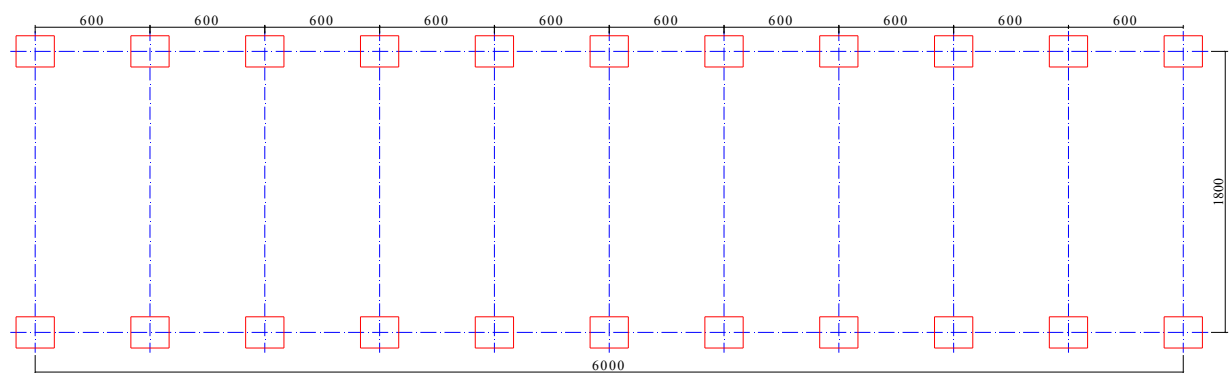

Slika 1. Dispozicija armirano-betonske montažne hale sa krovnim „A“ nosačem $l=18,0 \mathrm{~m}$ i rasterom stubova u podužnom smijeru $\lambda=6,0 \mathrm{~m}$

Urađene su dispozicije armirano-betonske montažne hale dim. 18,0 x 60 m sa sljedećim rasterom stubova u podužnom smijeru:

- 10 polja sa rasterom stubova u podužnom smijeru $\lambda=6,0 \mathrm{~m}$,

- 7 polja sa rasterom stubova u podužnom smijeru $\lambda=7,5 \mathrm{~m}$,

- 6 polja sa rasterom stubova u podužnom smijeru $\lambda=10,0 \mathrm{~m}$,

- 5 polja sa rasterom stubova u podužnom smijeru $\lambda=12,0 \mathrm{~m}$.

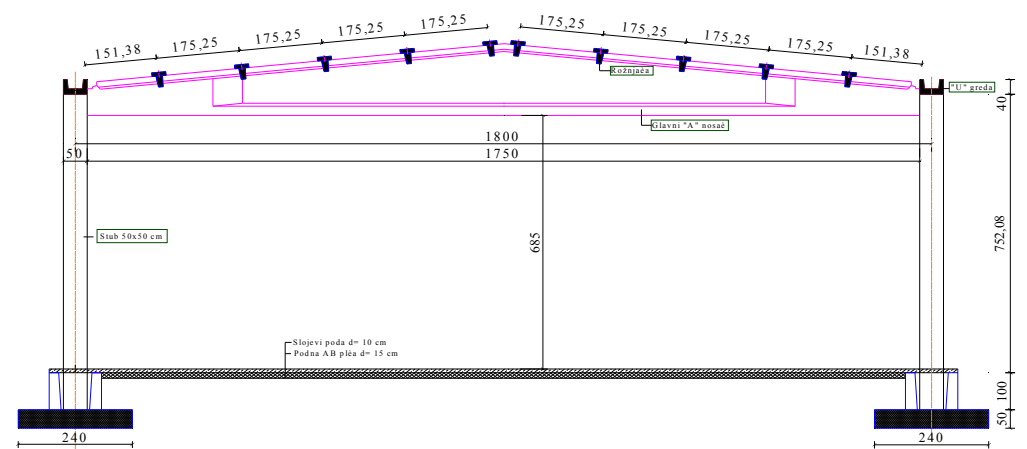

Slika 2. Poprečni presjek armirano-betonske montažne hale sa krovnim „A“ nosačem

$$
l=18,0 \mathrm{~m}
$$

Urađen je statički proračun, nacrti armature sa specifikacijama za izgradnju konstruktivnog dijela armirano-betonske montažne hale u četiri različita slučaja

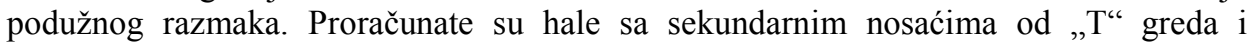
podužnim razmakom stubova i krovnih nosaća $(\lambda=6,0 \mathrm{~m}, 7,5 \mathrm{~m}, 10,0 \mathrm{~m}$ i $12,0 \mathrm{~m})$.

Predmetni objekti su jednobrodna prizemna hala svijetle visina od poda do rebra krovnog nosača $6,85 \mathrm{~m}$.

Svaka varijanta hale je računata na isto opterećenje koje iznosi: snijeg $=0,75 \mathrm{kN} / \mathrm{m}^{2}$, vjetar $=0,5 \mathrm{kN} / \mathrm{m}^{2}$, krovni pokrivač $=0,30 \mathrm{kN} / \mathrm{m}^{2}$, VII seizmička zona, nosivost tla $=250$ $\mathrm{kN} / \mathrm{m}^{2}$. Statički proračun i dimenzioniranje za svaku varijantu hale izvršeni su po istom principu uz uzimanje najnepovoljnijih slučajeva opterećenja.

\section{2}


Међународна конференција

Савремена достигнућа у грађевинарству 24. април 2015. Суботица, СРБИЈА

Konstruktivni sistemi razmatranih montažnih hala su skeletni i sastoje se od sljedećih elemenata: temeljne stope, temeljne grede, stubova, „U“ korito, krovni nosač tip „A“ i rožnjače.

\section{Temeljne stope}

Temeljenje konstrukcije izvršeno je na montažnim temeljima samcima. Temeljne stope su izvedene od betona MB 30 i armirane armaturom RA 400/500 kao i mrežama MAR $500 / 560$.

Tabela 1. Dimenzije temelja za pojedine podužne razmake stubova Konstruktivni sistem hale sa krovnim nosačem „A“ raspona 18,0 m

\begin{tabular}{cccc}
$\begin{array}{c}\text { Raster između stubova } \\
\lambda(\mathrm{m})\end{array}$ & $\begin{array}{c}\text { Dimenzije stope axb } \\
(\mathrm{cm})\end{array}$ & $\begin{array}{c}\text { Debljina stope } \\
\mathrm{d}(\mathrm{cm})\end{array}$ & $\begin{array}{c}\text { Visina čašice } \\
\mathrm{h}(\mathrm{cm})\end{array}$ \\
6,0 & $200 \times 200$ & 50,0 & 100,0 \\
\hline 7,5 & $220 \times 220$ & 50,0 & 100,0 \\
10,0 & $230 \times 230$ & 50,0 & 100,0 \\
12,0 & $240 \times 240$ & 50,0 & 100,0
\end{tabular}

\section{Temeljne grede}

Temeljne grede služe da povežu temeljne stope i da nose fasadu. Za slučajeve rastera "1" i "2" temeljne grede se oslanjaju na temeljne stope, dok se u slučajevima "3" i "4" oslanjaju i na međutemelje dimenzija $100 \times 100 \times 40 \mathrm{~cm}$. Veza temeljnih greda i temelja se vrši preko ankera koji se ugrađuju u temelj $\mathrm{i}$ ispuštene armature koja viri iz temeljnih greda. Temeljne grede su izvedene od betona MB 30 i armirane armaturom RA 400/500.

\section{Stubovi}

U temeljne stope su uklješteni montažni stubovi (hrapava veza) dimenzija 50x50 cm na koje se oslanjaju i zglobno vezuju poprečne i podužne montažne grede. Stubovi su izvedeni od betona MB 40 i armirani rebrastom armaturom RA 400/500. Stubovi su dimenzionirani na uticaje od krovne kostrukcije, krovnog nosača, U grede, vjetra, seizmičke sile. Proveden je proračun i za slučaj prilikom montaže stubova.

Veza između glavnog poprečnog "A" nosača, "T" presjeka i stuba se ostvaruje bolcnom promjera Ø22 i u eksploataciji radi kao zglobna veza.

\section{„U“ Korito}

"U" korita služe da preuzmu atmosfersku vodu i preko vertikalnih oluka sprovedu do terena. Dimenzioniranje "U" korita je rađeno na pripadajuće opterećenje sa krova (opterećenje od krovnog pokrivača, snijega i vjetra) i na opterećenja od sopstvene težine. Veza između podužnog nosača "U" presjeka (korita) i stuba ostvaruje se pomoću dva ankera Ø14 koji su ispušteni iz kratkih konzola stuba.

Krovni nosač tip , ,A“

Glavni krovni "A" nosač za usvojene raspone od 18 m je nagiba od 12,0\%. Na gornju stranu nosača oslanjaju se krovni elementi rožnjače "T" presjeka, koji služe kao nosači krovnog pokrivača (sendvič lim sa termikom), te opterećenja od vjetra i snijega.

Glavni krovni nosač je dimenzioniran na opterećenje od krova, rožnjača kao i od sopstvene težine. Izvršen je i kontrolni proračun za fazu transporta i montaže. Krovni nosač je izveden od betona MB 40 i armiran rebrastom armaturom RA 400/500. 
International conference

Contemporary achievements in civil engineering 24. April 2015. Subotica, SERBIA

\section{Rožnjače}

Rožnjače poprečnog presjeka „,T“ su dimenzionirane na opterećenja od krovnog pokrivača, snijega, vjetra i opterećenja od sopstvene težine.

Za usvojene konstruktivne sisteme odabran je i razmak rožnjača: za nosač od 18,00 m, usvojen je razmak rožnjače od $\lambda_{r}=175,25 \mathrm{~cm}$ i krajnji $\lambda_{r}=151,38 \mathrm{~cm}$. Rožnjače su usvojene poprečnog presjeka , $T^{“}$ visine $35 \mathrm{~cm}$ sa debljinom rebra od $\mathrm{d}=8,0 \mathrm{~cm}$ za osovinski razmak stubova $\lambda=6,0 \mathrm{~m}$ i $\lambda=7,5 \mathrm{~m}$ dok je usvojena visina $40 \mathrm{~cm}$ debljina rebra od $\mathrm{d}=10 \mathrm{~cm}$ za osovinski razmak stubova $\lambda=10,0 \mathrm{~m} \mathrm{i} \lambda=12,0 \mathrm{~m}$.

\section{REZULTATI ISTRAŽIVANJA}

$\mathrm{Na}$ osnovu nacrta hale, nacrta armature i specifikacije armature urađen je predmjer radova za betonske i armiračke radove za izgradnje hala za varijante podužnih razmaka stubova i krovnih nosaća $(\lambda=6,0 \mathrm{~m} ; 7,5 \mathrm{~m} ; 10,0 \mathrm{~m}$ i $12,0 \mathrm{~m})$. Izračunate potrebe armature i betona za izgradnju hale za svaki razmak stubova su prikazani tabelarno.

Tabela 2. Utrošak armature $i$ betona za izgradnju ab hale za raspon hale $l=18,0 \mathrm{~m} i$ raster stubova $\lambda=6,0 \mathrm{~m}$

\begin{tabular}{|c|c|c|c|c|c|}
\hline \multicolumn{6}{|c|}{ Utrošak armature i betona za izgradnju ab hale za raspon hale $1=18,0 \mathrm{~m}$} \\
\hline \multicolumn{6}{|c|}{ Raster između stubova $\lambda=6,0 \mathrm{~m}$} \\
\hline $\begin{array}{c}\text { Konstruktivni } \\
\text { element }\end{array}$ & $\begin{array}{c}\text { Broj } \\
\text { elemenata } \\
\text { (kom) }\end{array}$ & $\begin{array}{l}\text { Količina } \\
\text { armature po } \\
\text { elementu } \\
(\mathrm{kg} / \mathrm{kom})\end{array}$ & $\begin{array}{l}\text { Ukupna } \\
\text { količina } \\
\text { armature } \\
(\mathrm{kg})\end{array}$ & $\begin{array}{l}\text { Količina } \\
\text { betona po } \\
\text { elementu } \\
\left(\mathrm{m}^{3} / \mathrm{kom}\right)\end{array}$ & $\begin{array}{l}\text { Ukupna } \\
\text { količina } \\
\text { betona } \\
\left(\mathrm{m}^{3}\right)\end{array}$ \\
\hline Rožnjača & 120 & 63,41 & $7.609,20$ & 0,284 & 34,08 \\
\hline "U" greda & 20 & 77,63 & $1.552,60$ & 0,684 & 13,68 \\
\hline "A" nosač & 11 & 753,78 & $8.291,58$ & 4,893 & 53,82 \\
\hline Stub & 22 & 285,83 & $6.288,26$ & 1,940 & 42,68 \\
\hline \multirow{2}{*}{ Temeljna greda } & 24 & 49,08 & $1.177,92$ & 0,525 & 12,60 \\
\hline & 2 & 87,42 & 174,84 & 0,713 & 1,43 \\
\hline Temeljna stopa & 22 & 162,66 & 3578,52 & 2,810 & 61,82 \\
\hline Međutemelj & 6 & 13,69 & 82,14 & 0,400 & 2,40 \\
\hline UKUPNO & & & $28.755,06$ & & 222,51 \\
\hline
\end{tabular}

Tabela 3. Utrošak armature i betona za izgradnju ab montažne hale za raspon hale $l=18,0 \mathrm{~m}$ i raster stubova $\lambda=7,5 \mathrm{~m}$

Utrošak armature i betona za izgradnju ab montažne hale za raspon hale $1=18,0 \mathrm{~m}$

\begin{tabular}{|c|c|c|c|c|c|}
\hline \multicolumn{6}{|c|}{ Raster između stubova $\lambda=7,5 \mathrm{~m}$} \\
\hline $\begin{array}{c}\text { Konstruktivni } \\
\text { element }\end{array}$ & $\begin{array}{c}\text { Broj } \\
\text { elemenata } \\
\text { (kom) }\end{array}$ & $\begin{array}{c}\text { Količina } \\
\text { armature po } \\
\text { elementu } \\
\text { (kg/kom) }\end{array}$ & $\begin{array}{l}\text { Ukupna } \\
\text { količina } \\
\text { armature } \\
(\mathrm{kg})\end{array}$ & $\begin{array}{l}\text { Količina } \\
\text { betona po } \\
\text { elementu } \\
\left(\mathrm{m}^{3} / \mathrm{kom}\right)\end{array}$ & $\begin{array}{l}\text { Ukupna } \\
\text { količina } \\
\text { betona } \\
\left(\mathrm{m}^{3}\right)\end{array}$ \\
\hline ožnjača & 96 & 91,61 & $8.794,56$ & 0,360 & 34,56 \\
\hline "U" greda & 16 & 106,38 & $1.702,08$ & 0,864 & 13,82 \\
\hline "A" nosač & 9 & 780,85 & $7.027,65$ & 4,893 & 44,04 \\
\hline tub & 18 & 285,83 & 5.144 .94 & 1,940 & 34,92 \\
\hline
\end{tabular}

\section{4}


Међународна конференција

Савремена достигнућа у грађевинарству 24. април 2015. Суботица, СРБИЈА

$\begin{array}{lcrrrr} & 16 & 87,42 & 1.398,72 & 0,713 & 11,40 \\ \text { Temeljna greda } & 2 & 93,39 & 186,78 & 1,025 & 2,05 \\ & 4 & 49,08 & 196,32 & 0,525 & 2,10 \\ \text { Temeljna stopa } & 18 & 241,69 & 4.350,42 & 3,230 & 58,14 \\ \text { Međutemelj } & 6 & 13,69 & 82,14 & 0,400 & 2,40 \\ \text { UKUPNO } & & & \mathbf{2 8 . 8 8 3 , 6 1} & & \mathbf{2 0 3 , 4 3}\end{array}$

Tabela 4. Utrošak armature i betona za izgradnju ab montažne hale za raspon hale $l=18,0 \mathrm{~m}$ i raster stubova $\lambda=10,0 \mathrm{~m}$

Utrošak armature i betona za izgradnju ab montažne hale za raspon hale $1=18,0 \mathrm{~m}$

\begin{tabular}{|c|c|c|c|c|c|}
\hline \multicolumn{6}{|c|}{ Raster između stubova $\lambda=10,0 \mathrm{~m}$} \\
\hline $\begin{array}{l}\text { Konstruktivni } \\
\text { element }\end{array}$ & $\begin{array}{c}\text { Broj } \\
\text { elemenata } \\
\text { (kom) }\end{array}$ & $\begin{array}{l}\text { Količina } \\
\text { armature po } \\
\text { elementu } \\
(\mathrm{kg} / \mathrm{kom})\end{array}$ & $\begin{array}{l}\text { Ukupna } \\
\text { količina } \\
\text { armature } \\
(\mathrm{kg})\end{array}$ & $\begin{array}{l}\text { Količina } \\
\text { betona po } \\
\text { elementu } \\
\left(\mathrm{m}^{3} / \mathrm{kom}\right)\end{array}$ & $\begin{array}{l}\text { Ukupna } \\
\text { količina } \\
\text { betona } \\
\left(\mathrm{m}^{3}\right)\end{array}$ \\
\hline Rožnjača & 72 & 171,69 & $12.361,68$ & 0,630 & 45,36 \\
\hline "U" greda & 12 & 179,62 & $2.155,44$ & 1,164 & 13,97 \\
\hline "A" nosač & 7 & '973,41 & $6.813,87$ & 4,893 & 34,25 \\
\hline Stub & 14 & 285,83 & $4.001,62$ & 1,940 & 27,16 \\
\hline \multirow{2}{*}{ Temeljna greda } & 12 & 93,39 & $1.120,68$ & 1,025 & 12,30 \\
\hline & 2 & 87,42 & 174,84 & 0,713 & 1,43 \\
\hline Temeljna greda & 4 & 49,07 & 196,28 & 0,525 & 2,10 \\
\hline Temeljna stopa & 14 & 313,02 & $4.382,28$ & 3,455 & 48,37 \\
\hline Međutemelj & 18 & 13,69 & 246,42 & 0,400 & 7,20 \\
\hline UKUPNO & & & $31.453,11$ & & 192,13 \\
\hline
\end{tabular}

Tabela 5. Utrošak armature i betona za izgradnju ab montažne hale za raspon hale $l=18,0 \mathrm{~m}$ i raster stubova $\lambda=12,0 \mathrm{~m}$

Utrošak armature i betona za izgradnju ab montažne hale za raspon hale $\mathrm{l}=18,0 \mathrm{~m}$ Raster između stubova $\lambda=12,0 \mathrm{~m}$

$\begin{array}{lcrrrr}\begin{array}{l}\text { Konstruktivni } \\ \text { element }\end{array} & \begin{array}{c}\text { Broj } \\ \text { elemenata } \\ (\mathrm{kom})\end{array} & \begin{array}{c}\text { Količina } \\ \text { armature po } \\ \text { elementu } \\ (\mathrm{kg} / \mathrm{kom})\end{array} & \begin{array}{c}\text { Ukupna } \\ \text { količina } \\ \text { armature } \\ (\mathrm{kg})\end{array} & \begin{array}{c}\text { Količina betona } \\ \text { po elementu } \\ \left(\mathrm{m}^{3} / \mathrm{kom}\right)\end{array} & \begin{array}{c}\text { Ukupna } \\ \text { količina } \\ \text { betona } \\ \left(\mathrm{m}^{3}\right)\end{array} \\ \text { Rožnjača } & 60 & 232,11 & 13.926,60 & 0,760 & 45,60 \\ \text { "U" greda } & 10 & 266,86 & 2.668,60 & 1,404 & 14,04 \\ \text { "A" nosač } & 6 & 1.034,79 & 6.208,74 & 4,893 & 29,36 \\ \text { Stub } & 12 & 311,36 & 3.736,32 & 1,940 & 23,28 \\ & 10 & 153,31 & 1.533,10 & 1,275 & 12,75 \\ \text { Temeljna greda } & 2 & 87,42 & 174,84 & 0,713 & 1,43 \\ & 4 & 49,07 & 196,28 & 0,525 & 2,10 \\ \text { Temeljna stopa } & 12 & 316,34 & 3.796,08 & 3,630 & 43,56 \\ \text { Međutemelj } & 16 & 13,69 & 219,04 & 0,400 & 6,40 \\ \text { UKUPNO } & & & \mathbf{3 2 . 4 5 9 , 6 0} & & \mathbf{1 7 8 , 5 1}\end{array}$

\section{ANALIZA REZULTATA ISTRAŽIVANJA}

Na osnovu prethodnih tabela urađena je tabela 5. i tabela 6 , u kojima je prikazan ukupni utrošak armature i betona za izgradnju ab montažne hale za raspon hale $1=18,0 \mathrm{~m}$ za 
International conference

Contemporary achievements in civil engineering 24. April 2015. Subotica, SERBIA

slučajeve rastera između stubova u podužnom smjeru $(\lambda=6,0 \mathrm{~m}, \lambda=7,5 \mathrm{~m}, \lambda=10,0 \mathrm{~m}$ i $\lambda=12,0 \mathrm{~m})$.

Iz tabele 5. i tabele 6 . vidi se da je najmanji utrošak armature za izgradnju armirano-betonske montažne hale za raster $\lambda=6,0 \mathrm{~m}$, a najveći utrošak armature za raster $\lambda=12,0 \mathrm{~m}$, dok je najmanji utrošak betona za raster $\lambda=12,0 \mathrm{~m}$, a najveći za raster $\lambda=6,0 \mathrm{~m}$. Kada se kolićina armature pomnoži sa cijenom armature i kolićina betona pomnoži sa cijenom betona dobijemo da je povoljniji raster od $\lambda=12,0 \mathrm{~m}$,

Tabela 5. Ukupni utrošak armature za izgradnju ab montažne hale za raspon hale $l=18,0 \mathrm{~m}$ u zavisnosti od rastera između stubova

Ukupni utrošak armature za izgradnju ab montažne hale za raspon hale $1=18,0 \mathrm{~m}$ u zavisnosti od rastera između stubova u kg

\begin{tabular}{|c|c|c|c|c|}
\hline $\begin{array}{l}\text { Konstruktivni } \\
\text { elementi }\end{array}$ & $\begin{array}{l}\text { Raster između } \\
\text { stubova } \lambda=6,0 \mathrm{~m}\end{array}$ & $\begin{array}{l}\text { Raster između } \\
\text { stubova } \lambda=7,5 \mathrm{~m}\end{array}$ & $\begin{array}{l}\text { Raster između } \\
\text { stubova } \lambda=10,0 \mathrm{~m}\end{array}$ & $\begin{array}{c}\text { Raster između } \\
\text { stubova } \lambda=12,0 \mathrm{~m}\end{array}$ \\
\hline Rožnjače & $7.609,20$ & $8.794,56$ & $12.361,68$ & $13.926,60$ \\
\hline "U" grede & $1.552,60$ & $1.702,08$ & $2.155,44$ & $2.668,60$ \\
\hline "A" nosač & $8.291,58$ & $7.027,65$ & $6.813,87$ & $6.208,74$ \\
\hline Stub & $6.288,26$ & $5.144,94$ & $4.001,62$ & $3.736,32$ \\
\hline Temeljna greda & $1.177,92$ & $1.398,72$ & $1.120,68$ & $1.533,10$ \\
\hline Temeljna greda & 174,84 & 186,78 & 174,84 & 174,84 \\
\hline Temeljna greda & - & 196,32 & 196,28 & 196,28 \\
\hline Temeljna stopa & 3578,52 & $4.350,42$ & $4.382,28$ & $3.796,08$ \\
\hline Međutemelj & 82,14 & 82,14 & 246,42 & 219,04 \\
\hline UKUPNO & $28.755,06$ & $28.883,61$ & $31.453,11$ & $32.459,60$ \\
\hline
\end{tabular}

Tabela 6. Ukupni utrošak betona za izgradnju ab montažne hale za raspon hale $l=18,0$ $m$ u zavisnosti od rastera između stubova

\begin{tabular}{lrrrr}
\multicolumn{5}{c}{ Ukupni utrošak betona za izgradnju ab montažne hale za raspon hale $\mathrm{l}=18,0 \mathrm{~m}$ u zavisnosti } \\
\multicolumn{5}{c}{ od rastera između stubova $\mathrm{u} \mathrm{m}^{3}$} \\
Konstruktivni & $\begin{array}{c}\text { Raster između } \\
\text { elementi }\end{array}$ & Raster između & Raster između & Raster između \\
Rtubova $\lambda=6,0 \mathrm{~m}$ & stubova $\lambda=7,5 \mathrm{~m}$ & stubova $\lambda=10,0 \mathrm{~m}$ & stubova $\lambda=12,0 \mathrm{~m}$ \\
Rožnjače & 34,08 & 34,56 & 45,36 & 45,60 \\
"U" grede & 13,68 & 13,82 & 13,97 & 14,04 \\
"A" nosač & 53,82 & 44,04 & 34,25 & 29,36 \\
Stub & 42,68 & 34,92 & 27,16 & 23,28 \\
Temeljna greda & 12,60 & 11,40 & 12,30 & 12,75 \\
Temeljna greda & 1,43 & 2,05 & 1,43 & 1,43 \\
Temeljna greda & 61,82 & 2,10 & 2,10 & 2,10 \\
Temeljna stopa & 61,82 & 58,14 & 48,37 & 43,56 \\
Međutemelj & 2,40 & 2,40 & 7,20 & 6,40 \\
UKUPNO & $\mathbf{2 2 2 , 5 1}$ & $\mathbf{2 0 3 , 4 3}$ & $\mathbf{1 9 2 , 1 3}$ & $\mathbf{1 7 8 , 5 1}$
\end{tabular}

\section{ZAKLJUČAK}

Urađena je analiza svih prethodno navedenih tabela utroška armature i betona za izgradnju ab montažne hale za raspon hale $\mathrm{l}=18,0 \mathrm{~m}$, za pojedine podužne razmake stubova i glavnih krovnih nosača na osnovu kojih se došlo do sljedećih zaključaka:

\section{6}


Међународна конференција

Савремена достигнућа у грађевинарству 24. април 2015. Суботица, СРБИЈА

- Najveći utrošak armature za predmetnu montažnu halu je za raster $\lambda=12,00 \mathrm{~m}$, a najmanji za raster $\lambda=6,0 \mathrm{~m}$;

- Najveći utrošak betona za predmetnu montažnu halu je za raster $\lambda=6,00 \mathrm{~m}$, a najmanji za raster $\lambda=12,00 \mathrm{~m}$;

- Imajući u vidu da se transport i ugradnja računa na osnovu kolićine betona, slijedi da je najveća cijena transporta, montaže, radne snage, pokrivača za predmetnu montažnu halu za raster $\lambda=6,00 \mathrm{~m}$, a najmanja za raster $\lambda=12,00 \mathrm{~m}$;

- Najveća ukupna cijena izgradnje predmetne montažne hale je za raster $\lambda=6,00 \mathrm{~m}$, a najmanja za raster $\lambda=12,00 \mathrm{~m}$;

- Preporuka autora budućim projektantima je da kod projektovanja prizemnih hala uzimaju rastere 10-12 m jer sa povećanjem rastera raste ekonomičnost, ali kod povećanja preko $12 \mathrm{~m}$ bi ekonomićnost trebalo provjeriti novim istraživanjem, jer su ova istraživanja rađena u rasponu od 6-12 m.

- Povećenje rastera je ogranićeno jer se oćekuje da poslije određenog rastera troškovi znatno rastu.

\section{LITERATURA:}

[1] Gušić, I.: Organizacija građenja, Papir karton, Tuzla, 2012.

[2] Hasanović, V.: Betonske konstrukcije zbirka riješenih zadataka, Sejtarija d.o.o, Sarajevo, 2005.

[3] Hasanović, V.: Betonske konstrukcije, "Mušinović" d.o.o. Brčko Distrikt, Sarajevo, 2007.

[4] Standardne norme u građevinarstvu

[5] Trbojević, B.: Organizacija građevinskih radova, Naučna knjiga, Beograd, 1992. 


\title{
THE CONSUMPTION OF WELDED WIRE MESH AND CONCRETE IN BUILDING THE CONSTRUCTIVE PART OF THE REINFORCED-CONCRETE PREFABRICATED HALL DEPENDING ON THE LENGTHWISE SPAN BETWEEN THE PILLARS AND MAIN SUPPORTS
}

\begin{abstract}
Summary: The paper studies the consumption of welded wire mesh and concrete in the construction of reinforced-concrete prefabricated halls, depending on the extended span of pillars and main supports. The required data were obtained by means of statistical calculations, welded wire mesh sketches, welded wire mesh specifications for the constructive part of the reinforced-concrete prefabricated hall in four different cases of the extended span of roof supports type " $A$ " with the same span of $l=18.0 \mathrm{~m}$. Premeasurement halls are calculated with the extended span of roof supports $(\lambda=6.0 \mathrm{~m}$, $7.5 \mathrm{~m}, 10.0 \mathrm{~m}$ and $12.0 \mathrm{~m}$ ). Based on the facility sketches, welded wire mesh sketches, and welded wire mesh specifications, the pre-measurement of concrete and welded wire mesh was made for the hall disposition with the extended span of pillars and roof supports $(\lambda=6.0 \mathrm{~m}, 7.5 \mathrm{~m}, 10.0 \mathrm{~m}$ and $12.0 \mathrm{~m})$. The resulting values of the required welded wire mesh and concrete are presented in tables and diagrams. Based on the tables and diagrams for the required welded wire mesh and concrete for the construction of prefabricated reinforced-concrete hall for individual lengthwise spans of pillars and main supports, the summarized data table was made. The analysis of the summarized table led to the conclusion regarding the most favorable span within the scope of those examined, and recommendations were given to prospective planners.
\end{abstract}

Key words: prefabricated constructions, armature, concrete, span and most favorable span 